\title{
Evaluation of the Chemical Effects of the Drugs with Xerostomy Effect on the Oral Cavity
}

\author{
CATALINA IULIA SAVEANU ${ }^{1}$, LENUTA LACRAMIOARA UNGUREANU TITEI ${ }^{1}$, ANCA MELIAN2*, DANIELA ANISTOROAEI'*, \\ ADINA OANA ARMENCIA', SORIN ANDRIAN², ALEXANDRA ECATERINA SAVEANU1, GABRIELA IORGULESCU ${ }^{3}$ \\ ${ }^{1}$ University of Medicine and Pharmacy Grigore T. Popa, Faculty of Dental Medicine, Department of Surgery, 16 Universitatii Str., \\ 700115, Iasi, Romania \\ 2University of Medicine and Pharmacy Grigore T. Popa, Faculty of Dental Medicine, Odontology, Periodontology, Fixes Restorations \\ Department, 16 Universitatii Str. , 700115, lasi, Romania \\ ${ }^{3}$ University of Medicine and Pharmacy Carol Davila, Dental Medicine Faculty, 19 Calea Plevnei, 010221, Bucharest, Romania
}

\begin{abstract}
Medications are the primary etiologic factor in the appearance of xerostomia, dysfunction subjectively perceived by the patient as the sensation of dry mouth. The purpose of this study was to evaluate the knowledge and attitudes towards oral health in a group of adults undergoing treatment with drugs that have a secondary effect of xerostomia. The study was conducted on a sample of 64 adults with a mean age of 46-65 years with at least one chronic condition treated with at least one of the following drugs: antihypertensive, anticholinergic, antihistamine, anti-asthmatic, anxiolytic, antiparkinson, chemotherapy, oral antidiabetics, antineoplastic, antirheumatic. The results of the study show that following the administration of any of the classes of drugs administered, the side effect of xerostomia was manifested in all patients.
\end{abstract}

Keywords: xerostomia, drymouth, antihypertensive, anticholinergic, antihistamine, anxiolytic, antiparkinson, chemotherapy, antidiabetics, antineoplastic, antirheumatic

Xerostomy or dry mouth sensation is considered a complex condition that affects several dental functions, affecting their quality of life. Often, xerostomia is accompanied by a decrease in salivary flow with consequences on oral health. [1] Currently, the diagnosis and treatment methods for this condition are varied and it is difficult to obtain favorable results in all cases, as the etiology seems to be multifactorial where both local and systemic factors would participate [2-5]. Although xerostomia may occur frequently in the general population, clear and defined tools are needed for diagnosis and treatment. Today, patients suffering from xerostomia consult many health professionals to resolve this complex condition. Medications are most commonly incriminated in the occurrence of xerostomia, dysfunction subjectively perceived by the patient as dry mouth sensation. Because of the subjective appreciation and in the context of diseases that are much more invalid for the patient, xerostomia is mostly unconscious. The overlooking of such a condition, logically leads to a lack of attitude of the patient, regarding the taking of preventive measures in front of the adverse consequences that may occur in the oral cavity. The increased prevalence of chronic diseases that have been associated with a hyposialic medication is a pertinent reason for evaluating the hyposiality in order to ensure a sustained prevention of the oral cavity. Adult patients most often associate besides significant caries experience, multiples, controllable risk factors (hygiene, diet, periodic controls) and uncontrollable risk factors not salivary hyposecretion. The purpose of this study was to evaluate the knowledge and attitudes towards oral health in a group of adults undergoing treatment with hyposial medication. The specific objectives were: to determine the prevalence of xerostomia, as a subjective manifestation of hyposiality by age groups, sex, type of pathology, type of medication, assessment of knowledge level and attitude regarding xerostomia.

\section{Experimental part}

The study was conducted on a sample of 64 adults with an average age of $46-65$ years. The inclusion criteria were for the age of the subjects to be over 18 years old and to present at least one chronic condition treated daily with medication belonging to any of the following therapeutic classes: antihypertensive, anticholinergic, antihistamine, anti-depressant, antidepressant, anxiolytic, antiParkinson's, chemotherapy, antineoplastic, antirheumatic. The data were collected on the basis of a questionnaire, designed in the theme of this study, which included 47 questions, regarding the patients' knowledge and attitudes regarding the causes, complications and importance of the treatment of hyposiosia., Questions for the evaluation of oral status (OS) (self-report of gingival bleeding, dental mobility, dental sensitivity, untreated caries, compromised treatments, halitosis, xerostomia, edentatives., questions regarding knowledge and attitudes towards gold-dental hygiene, diet, frequency of controls. Participation of the subjects was voluntary, anonymous and based on consent. The selection of the batch was carried out in the waiting rooms of several medical units in lasi as well as the specialized ambulatory of the Spiridon Polyclinic (Allergology, Pneumology, Mental Health). The data were entered and processed statistically in the program SPSS 14.00 for W indows, with statistical significance of $p \leq 0.05$.

\section{Results and discussions}

The results of the study indicate that the subjects were $57.81 \%$ female and $42.19 \%$ male. Subjects were included in the following age groups, respectively $18-25$ years $6.3 \%$ (4), $26-35$ years $14.1 \%(9)$, 36-45 years $14.1 \%(9), 46-65$ of years, $48.4 \%$ (31), more than 65 years $17.2 \%$ (11). The study participants came from different social categories $40.62 \%$ having high school, $25.0 \%$ university studies, $20.31 \%$ elementary studies and $14.06 \%$ postgraduate studies. Most of the subjects were from the rural area

\footnotetext{
*email: meliananca@yahoo.com, Phone: 075778188; cmiortodent@yahoo.com, Phone: 0721377269
} 
$71.88 \%$. All subjects included in the study had at least one general condition, thus distributing $54.7 \%$ (35) cardiovascular disease, $26.6 \%$ (17) respiratory or allergic disease 26.6 (17), CNS affect 15, 6\% (10), gastrointestinal disorders $10.9 \%$ (7), endocrine disorders 14\%, 1(9), urinary disorders $4.7 \%(3)$, liver disorders, $9.4 \%$ (6), disorders autoimmune $9.4 \%$ (6), radiotherapy area / head neck $4.7 \%$ (3). Asked about the causes of xerostomia, $45.31 \%$ of the subjects answered yes and 54.69\% negative. The answers to the question about the complications of xerostomia reveal that $65,62 \%$ of the subjects do not know the complications of xerostomia in the oral cavity, while $34.38 \%$ answered yes. When asked abouttreatment, most subjects $76.56 \%$, stated that they do not perform a home xerostomia treatment. Ask about occupational prevention $68.75 \%$ of the subjects answered negative, $12.5 \%$ of the subjects said they did not have this problem, and $18,75 \%$ of the subjects answered yes, regarding the addressability to the doctor $59,38 \%$ of doubters find it very important and $40,62 \%$ do not. For the question Have you ever addressed a professional (family doctor, dentist, pharmacist) for the treatment of dry mouth? only $18,75 \%$ of the subjects answered yes while $81.25 \%$ answered negative. When asked about the state of dental hygiene, $59.38 \%$ of the subjects stated that they had soft tissue and deposits and $40.62 \%$ of the subjects answered negative. To the question about the presence of dental mobility, $40.62 \%$ of the subjects answered yes and $59.38 \%$ answered no. Distribution of answers to questions At present, you have one of the following problems: sensitive teeth is $64.1 \%$ (41) that yes, for the question Do you have cured or pigmented teeth $64.06 \%$ (31) have said yes, defective obturations $48.4 \%$ (31), root residues $29.69 \%$. Distribution of answers to the question Do you have an unpleasant odor of oral cavity? was $43.75 \%$ (28) for those who answered yes to the question Do you suffer from drymouth? $50 \%$ have declared that not even before, only 15\% had declared that they are suffering from this condition. $75 \%$ (48) of the respondents intend to refer the dentist for the existing problems and $43.75 \%$ (28) have answered positively.

When asked Do you consider it normal for teeth to age with age? $15.6 \%$ (10) subjects answered that they avoid oral-dental hygiene if they bleed the gums, and $9.4 \%$ (6) do not know what attitude to take, $10 \%$ (7) avoid teeth hygiene when the teeth are sensitive. $32.8 \%$ (21) of the subjects do not consider that they should consult the dentist if they do nothave toothache, $6.3 \%$ (4) do notknow. Also the answers to the question Do people with dry mouth have a higher risk of caries? they pointed out that $54.69 \%$ of them do not know about the existence of this risk. Only 58.38\% (38) are aware that certain medications can give a dry mouth, $32.8 \%$ (21) that it is normal for the mouth to be drier, 34.4 (22) not knowing this. The attitudes regarding the nutrition genius have obtained the following results. For the question Are small and frequent snacks throughout the day harmful to the teeth? $64 \%$ (41) state that they do not know this fact, but mostly $87.5 \%$ (56) believe that sugary carbonated juice is harmful to the teeth. The vast majority of subjects prefer the treatment of dental lesions instead of extraction $78.12 \%(50)$ over $7.8 \%(5)$. There remains a percentage of $7.8 \%$ (5) who do not use toothpaste and toothbrush for hygiene and $60.9 \%$ (39) do not use mouth water, $75 \%$ (48) do not use interdental floss or brushes $78.12 \%$ (50). The majority of the subjects use interdental brushes for oral hygiene, $98.4 \%$ (63) compared to $1.6 \%(1)$, and $79.7 \%(51)$ compared to $20.3 \%$ (17) use chewing gum. Dental brushing is never $3.1 \%(2)$, several times a year $3.1 \%(2)$ and several times a week $15.6 \%$ (10). $53.1 \%$ (34) compared to $46.9 \%$
(30) are accustomed to rinsing their mouth after each meal and $26.6 \%$ equally consider that morning brushing is as important as evening brushing, $35.9 \%$ (23) considering that only the morning and 37.5 (24) considering that only the evening. On average, the duration of dental brushing is given less than 1 minute $14.1 \%(9), 1$ minute $28.1 \%(18), 2$ minutes $43.8 \%$ (28), 3-5 minutes $14.1 \%$ ( 9 ) 37.5 (24) do not know if they use fluoride toothpaste, $15.6 \%$ (10) yes and $46.9 \%(30)$ no, $95.3 \%(61)$ as against $4.7 \%(3)$ it does not use interdental wire, 39.1 (25) does not use mouth water and $26.6 \%$ of those who use it do not know what their mouth water contains, and equally $17.2 \%$ ( 11) states that their mouth water contains alcohol, respectively fluorine. Also $17.2 \%$ (11) compared to $82.8 \%$ had professional fluoridation in the cabinet and $60.9 \%(39)$ had professional hygiene compared to 39.1 (25) that they did not. To the question How often do you eat between the main tables or drink sugary, flat or sour juices the subjects answered mainly that $1-2$ times a day $37.5 \%$ (24) 2-3 times a day $12.5 \%$ (8) and more than 3 times $10.9 \%$ (7) from time to time but not every day $31.3 \%$ (20) I never eat between meals $7.8 \%$ (5), $20.3 \%$ (13) compared to 79.7 (51) are tobacco and coffee consumers. Water consumption was 2 liters per day for $25 \%$ (16) of the respondents, less than 2 liters for $59.4 \%$ (38) and more than 2 liters for $15.6 \%(10), 17,2 \%$ (11) taking a mouthdrying medicine, $35.9 \%$ (23) do not know if they take a mouth-drying medicine and $46.9 \%$ (30) say they do not take any mouth-drying medicine. The correlation of the responses of the subjects with general affections regarding the symptomatology felt emphasized that although the symptoms of hyposiosia appeared in many situations there are no statistically significant differences $p \geq 0.05$. The correlation of the responses of the subjects with general disorders regarding the fact that they often have the sensation of dry mouth indicates that in general there are no statistically significant differences in particular they are present in the patients with diseases of the central nervous system and renal diseases $p<0.05$ (Table 1)

The correlation of the answers of the subjects with general affections regarding the question On a scale of 0 (not at all) to 10 (extremely annoying) how much it will affect the sensation of dry mouth indicates that in general there are no statistically significant differences in particular. being present in patients with nervous and renal diseases $\mathrm{p}<0.05$ (Tab. 2)

Xerostomia is a symptomatology frequently seen in dental practice, has many negative effects on oral health and can have a negative impact on quality of life. The specialized literature reports high prevalence values with variations between geographical areas and age groups and due to differences in inclusion criteria and study methodology [2]. Epidemiological studies reported its prevalence between 0.9 and $64.8 \%$ [3]. In this study the prevalence of xerostomia reported often and very often was $17 \%$. Xerostomy is more common in women, and its prevalence is highest after age 60, probably due to increased drug intake, due to chronic disorders, such as hypertension, diabetes, depression, etc.; $[10,11]$ however, there are reports that age itself acts as a risk factor for xerostomia. Field et al. [12] reported that drug use and age independently increase the likelihood of developing xerostomia 1.24 times every 10 years. The same authors also reported a nearly fourfold prevalence of xerostomia in patients taking drugs (28\%), compared to those not taking any (7.5\%). It has been reported that not only the type of drug, but also the number of drugs taken (polypharmacy or simultaneous use of several drugs) increases the likelihood of developing xerostomia, which is a common 
Table 1

CORRELATION OF THE RESPONSES OF THE SUBJECTS WITH GENERAL AFFECTIONS REGARDING THE FACT THAT THEY OFTEN HAVE A DRY MOUTH

\begin{tabular}{|c|c|c|c|c|c|c|c|c|}
\hline \multirow[t]{2}{*}{ Follow a chronic disease treatment } & \multicolumn{6}{|c|}{$\begin{array}{l}\text { Do you often feel that your mouth is } \\
\text { dry? }\end{array}$} & \multirow[b]{2}{*}{ Total } & \multirow[t]{2}{*}{$\mathrm{p}$} \\
\hline & A & $\bar{B}$ & $\mathrm{C}$ & $\mathrm{D}$ & $E$ & F & & \\
\hline Cardiovascular & 2 & 10 & 17 & 2 & 3 & 1 & 35 &, 894 \\
\hline Respiratory and allergic & 0 & 7 & 6 & 1 & 2 & 1 & 17 &, 336 \\
\hline CNS and psychiatric & 0 & 3 & 3 & 0 & 3 & 1 & 10 & 011 \\
\hline Gastric & 0 & 1 & 4 & 0 & 2 & 0 & 7 & 293 \\
\hline Endocrine, nutrition and metabolism & 1 & 2 & 6 & 0 & 0 & 0 & 9 &, 628 \\
\hline Kidneys & 0 & 0 & 1 & 0 & 2 & 0 & 3 &, 008 \\
\hline Liver & 1 & 1 & 0 & 0 & 1 & 0 & 3 &, 370 \\
\hline Autoimmune & 0 & 2 & 3 & 0 & 1 & 0 & 6 &, 925 \\
\hline Sjogren's syndrome, & 0 & 0 & 0 & 0 & 0 & 0 & 0 & - \\
\hline Do radiation therapy to the neck area & 0 & 0 & 3 & 0 & 0 & 0 & 3 &, 646 \\
\hline
\end{tabular}

Table 2

CORRELATION OF THE ANSWERS OF THE SUBJ ECTS WITH GENERAL AFFECTIONS WITH THE ANSWERS TO THE QUESTION ON A SCALE OF 0 (NOT AT ALL) TO 10 (EXTREMELY ANNOYING) HOW MUCH WILL THE DRY MOUTH AFFECT?

\begin{tabular}{|c|c|c|c|c|c|c|c|c|c|c|c|c|c|}
\hline \multirow[t]{2}{*}{$\begin{array}{l}\text { General conditions - the question Follow } \\
\text { chronic treatment for diseases }\end{array}$} & \multicolumn{11}{|c|}{$\begin{array}{l}\text { On a scale of } 0 \text { (not at all) to } 10 \text { (extremely } \\
\text { annoying) how much does the dry mouth feel } \\
\text { affect you? }\end{array}$} & \multirow[t]{2}{*}{ Total } & \multirow[t]{2}{*}{$\mathrm{p}$} \\
\hline & 0 & 1 & 2 & 3 & 4 & 5 & 6 & 7 & 8 & 9 & 10 & & \\
\hline Cardiovascular & 7 & 6 & 6 & 3 & 1 & 6 & 1 & 1 & 2 & 1 & 1 & 35 &, 734 \\
\hline Respiratory and allergic & 1 & 2 & 3 & 2 & 3 & 3 & 1 & 0 & 1 & 1 & 0 & 17 &, 527 \\
\hline CNS and psychiatric & 4 & 0 & 1 & 0 & 0 & 1 & 1 & 0 & 2 & 1 & 0 & 10 &, 036 \\
\hline Gastric & 3 & 0 & 0 & 0 & 1 & 2 & 1 & 0 & 0 & 0 & 0 & 7 &, 574 \\
\hline Endocrine, nutrition and Metabolism & 1 & 2 & 0 & 1 & 1 & 2 & 1 & 1 & 0 & 0 & 0 & 9 &, 794 \\
\hline Kidneys & 0 & 0 & 0 & 1 & 0 & 1 & 0 & 0 & 0 & 1 & 0 & 3 &, 006 \\
\hline Liver & 2 & 0 & 0 & 0 & 0 & 1 & 0 & 0 & 0 & 0 & 0 & 3 & 910 \\
\hline Autoimmune & 3 & 0 & 0 & 0 & 2 & 1 & 0 & 0 & 0 & 0 & 0 & 6 &, 235 \\
\hline Sjogren's syndrome, & 1 & 0 & 0 & 2 & 0 & 0 & 0 & 0 & 0 & 0 & 0 & 3 & 319 \\
\hline
\end{tabular}

feature in elderly patients [13]. Patients with xerostomia may complain of burning sensation, abnormal taste, dysarthria, dysphagia, dysphagia, halitosis, and lack of prosthesis retention. Examination may demonstrate the dry appearance of the oral mucosa, increased salivary viscosity, candidiasis (usually angular cheilitis or erythematous candidiasis), cracking and depapilation of the tongue, cervical cavity, and halitosis [14]. It has been documented that xerostomia is a good predictor of root caries development in elderly patients [15]. Xerostomy is correlated with low salivary flow (hyposalivation). However, many patients have dry mouth, with normal salivary flow; therefore, xerostomia does not reflect the need for salivary gland hypofunction. Hyposialia is defined as an objective reduction of salivary flow. Saliva is usually classified as unstimulated (re-stimulated) or stimulated. Unstimulated saliva reflects the basal flow aimed at protecting the mucous membrane of the mouth, and has been reported to range from about $0.29 \mathrm{ml} / \mathrm{min}$ to $0.4 \mathrm{ml}$ / min. Stimulated saliva aids chewing and digestion and has been reported to be between 1-2 $\mathrm{ml} / \mathrm{min} .1$. Xerostomia has many negative effects on oral health and can have a negative impact on quality of life. Patients with xerostomia may have a burning sensation, abnormal taste, 


\begin{tabular}{|l|c|}
\hline Correlations between different questions that underline aspect of xerostomia & $\mathrm{p}$ \\
\hline Number of medicines taken daily * Dry mouth sensation & .107 \\
\hline Gums bleeding * Avoid oral or dental hygiene & .954 \\
\hline Teeth sensitivity * Avoidance of oral and dental hygiene & .358 \\
\hline Presence of carious lesions * Presentation at the control in the absence of pain & .623 \\
\hline The presence of incorrect restorations * Presentation to the control in the absence of pain & .082 \\
\hline Presence of root residues * Presentation at the control in the absence of pain & .589 \\
\hline Presence of halitosis* Presentation at the control in the absence of pain & .565 \\
\hline Mouth dryness * Presentation at the control in the absence of pain & .964 \\
\hline Presence of soft/hard deposits * Presentation at the control in the absence of pain & .162 \\
\hline The presence of mobile teeth * Presentation at the control in the absence of pain & .687 \\
\hline Do I drink coffee? * Dry mouth sensation & .500 \\
\hline Do I use cigarettes? * Dry mouth sensation & .366 \\
\hline Daily water consumption * Dry mouth sensation & .027 \\
\hline
\end{tabular}

Table 3

CORRELATION OF THE ANSWERS OF THE SUBJECTS WITH RESPECT TO DIFFERENT QUESTIONS THAT EMPHASIZE ASPECT OF XEROSTOMIA dysarthria, dysphagia, halitosis and lack of prosthesis retention.

\section{Conclusions}

W ithin the limits of this study we can state the following conclusions: Although all the participants involved in the study had symptoms of hyposia, only $15 \%$ of them showed it often and very often. The taste, speech and swallowing of the patients with hyposialic medication is present in one third of the cases but treatment for this is followed by only $5 \%$ of the subjects. Half of the subjects do not know the causes and complications of dry mouth. The thirst sensation that appeared during sleep is present in more than two thirds of the studied group. Only about $20 \%$ follow a treatment for the prevention of cavities, including the use of adjuvant means, although all the respondents know that they must consult a professional for the symptomatology given by hyposialia, $75 \%$ declaring their intention to address the dentist for dental problems. The level of knowledge and attitudes regarding dental hygiene is remarkable considering that half of them perform the brushing twice a day even though the affected time is reduced only $15 \%$ by doing it properly and $65 \%$ of them state that they use tap water. mouth, $28 \%$ being aware of the unpleasant odor of the oral cavity. Although it suffers from dry mouth $17 \%$ uses mouth water with alcohol. Subjects not knowing its side effects $40 \%$ of subjects do not know that certain medications can give dry mouth, they are not convinced of the regular address of the dentist, although they know that people with dry mouth have a higher risk of developing caries lesions (60\%) $64 \%$ do not know that hyposialia can be attributed to aging and I do not know that snacks between meals are harmful to the elderly, and most of them incriminate the carbonated juices. Although half of the patients were given 1-2 medicines a day, the rest, 35\% do not know if the medicines taken have a hyposial medication and $60 \%$ consume less than two liters of water a day. Only about $20 \%$ of patients are consuming coffee and tobacco but in general, the number of snacks between meals is not alarming. Of the medications given to the various pathologies, only subjects with medication for CNS and urinary tract disorders have symptoms of dry mouth $p<0.05$, which leads us to think that the disease itself may have an effect on salivary flow, there are no statistically significant differences between the number of medicines administered daily and the sensation of dry mouth.

\section{References}

1.ATKINSON JC, GRISIUS M, MASSEY W. Dental Clinics of North America. 2005;49:309-326. DOI:10.1016/j.cden.2004.10.002 26 Salivary Glands New Approaches in Diagnostics and Treatment

2.GRISIUS MM. Oral Surgery,Oral Medicine, Oral Pathology, Oral Radiology, and Endodontics. 2001;92:156-162. DOI:10.1067/ moe.2001.116601

3.MIRANDA-RIUS J, BRUNET-LLOBET L, LAHOR-SOLER E, FARRE M. International J ournal of Medical Sciences. 2015;12:811-824. DOI: 10.7150/ ijms.12912

4.PORTER SR, SCULLY C. Clinics in Dermatology. 2000;18:525-532

5.WIENER RC, WU B, CROUT R, WIENER M, PLASSMAN B, KAO E, MCNEIL D. J ournal of the American Dental Association (1939). 2010;141:279-284

6.I. DANILA, Dentistica Preventiva, Editura Didactica si Pedagogica 2005

7.SHIP JA, FOX PC, MICHALEK JE, CUMMINS MJ, RICHARDS AB. J ournal of Interfero\& Cytokine Research. 1999;19:943-951. DOI: 10.1089/ 107999099313497

8.GURVITS GE, TAN A. World J ournal of Gastroenterology. 2013;19:665672. DOI: 10.3748/wjg.v19.i5.665

9.BOSSOLA M, TAZZA L. Nature Reviews.Nephrology. 2012;8:176-182. DOI: 10.1038/nrneph.2011.218

10.IVANOVSKI K, NAUMOVSKI V, KOSTADINOVA M, PESEVSKA S, DRIJANSKA K, FILIPCE V. Prilozi. 2012;33:219-229

11.TANASIEWICZ M, HILDEBRANDT T, OBERSZTYN I. Advances in Clinical and Experimental Medicine. 2016;25:199-206. DOI10.17219/ acem/29375

12.NAPENAS JJ, BRENNAN MT, FOX PC. Odontology. 2009;97:76-83. DOI: 10.1007/s10266-008-0099-7

13.HOPCRAFT MS, TAN C. Australian Dental J ournal.2010;55:238-244. DOI: 10.1111/j.1834-7819.2010.01229.x. quiz 353

14.LLENA-PUY C. Medicina Oral, Patología Oral y Cirugía Bucal. 2006;11:E449-E455

15. DJ O, LEE JY, KIM YK, KHO HS. International J ournal of Oral and MaxillofacialSurgery. 2008; 37:1027-1031. DOI: 1

Manuscript received: 15.02 .2019 